\title{
Preparation of PVA-Based Composites with the Addition of Zinc Oxide Nanoparticles
}

\author{
Jolanta Pulit-Prociak ${ }^{1}$ - Krzysztof Pszczółka ${ }^{1} \cdot$ Jarosław Chwastowski ${ }^{1} \cdot$ Paweł Staroń $^{1} \cdot$ Anita Staroń $^{1}$. \\ Elżbieta Sikora ${ }^{2} \cdot$ Sławomir Michałowski ${ }^{3} \cdot$ Marcin Banach $^{1}$
}

Received: 19 September 2018 / Accepted: 21 October 2018 / Published online: 25 October 2018

(C) The Author(s) 2018

\begin{abstract}
The paper presents the possibility of obtaining poly(vinyl alcohol)-based coatings containing zinc oxide nanoparticles. The research part has been divided into three steps. At the beginning, nanometric zinc oxide was produced by the hydrothermal method and its physicochemical properties were characterized. The second part of the research included the creation of a reference composition. Next, three independent variables were determined: the mixing temperature of composites, the concentration of glycerine and the concentration of nanometric zinc oxide that could affect the properties of products. In the last stage, the compositions were tested for physicochemical, utility and microbiological properties. Based on the conducted tests it was found that the composites have antimicrobial properties. Nanocrystalline zinc oxide is eluted from the composites in trace amounts and thus the products are safe for the environment. Among the independent variables, only the temperature affects utility properties of the obtained products. A product with the best functional properties is intended to be applied in a suspension form on the surface that is microbially infected and, after its solidification, it can be removed together with dead biological material.
\end{abstract}

Keywords Zinc oxide $\cdot$ PVA $\cdot$ Functional coatings $\cdot$ Antimicrobial effect $\cdot$ Solidification

\section{Introduction}

The development of science allows us to become better acquainted with the threats that microorganisms pose to human beings. Raising awareness about compliance with the principles of cleanliness helps to prevent the spread of diseases; however, the level of hygiene of many people still

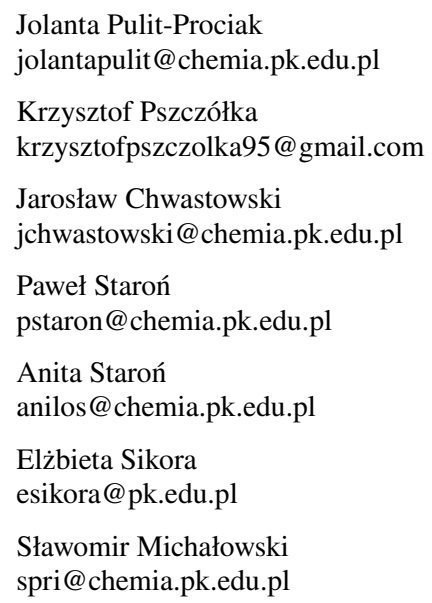

leaves much to be desired. In order to maintain cleanliness in public places, scientists are looking for new solutions that allow for the development of more effective cleaning products.

Pools, water parks, and public baths are places where high moisture levels persist and the temperature is a few degrees higher than room temperature. These are excellent
Marcin Banach

marcinbanach@chemia.pk.edu.pl

1 Faculty of Chemical Engineering and Technology, Institute of Chemistry and Inorganic Technology, Cracow University of Technology, Warszawska 24, 31-155 Cracow, Poland

2 Faculty of Chemical Engineering and Technology, Institute of Organic Chemistry and Technology, Cracow University of Technology, Warszawska 24, 31-155 Cracow, Poland

3 Faculty of Chemical Engineering and Technology, Department of Chemistry and Technology of Polymers, Cracow University of Technology, Warszawska 24, 31-155 Cracow, Poland 
conditions for the development of microorganisms, such as bacteria or fungi. The most common disease for athletes and people using the above-mentioned places is the "athlete's foot" [1].

Another example of problematic public places in which diseases can spread are gyms. The number of people using fitness centres increases year by year, which is a positive trend. Unfortunately, many people cannot adequately care for the cleanliness of exercise equipment, which is the cause of disease transmission. Surfaces in contact with human sweat are an ideal place for the development of microorganisms. The most common diseases that can be contracted are primarily skin diseases such as, for example, oedemas and tinea pedis [2].

With the development of nanotechnology, the influence of nanomaterials on bacteria and fungi is more and more often studied, considering them as an opportunity to raise the level of hygiene in public places [3]. Currently, research is being carried out on effective methods of destroying the habitats of microorganisms using materials containing nanoparticles of metals and metal oxides such as nanometer silver, titanium oxide or zinc oxide. The last of the mentioned ones is characterized by good electrical, photochemical, catalytic and optical properties. It is used, inter alia, as a component of biomimetic membranes. In addition, it can immobilize and modify proteins due to a rapid transfer of electrons between the enzyme and electrode sites. Zinc oxide has many advantages, one of which is a noticeable activity in the range of neutral $\mathrm{pH} 7-8$; it is also non-toxic and stable under the influence of both UV radiation and high temperatures [4]. All this makes the nanometric $\mathrm{ZnO}$ a subject of research by scientists.

The interest in developing new organic-inorganic nanocomposites is growing year by year. The embedding of metallic oxide nanoparticles in the structure of polymeric matrix has a great importance due to novel properties derived from the developed material $[5,6]$. For example, introducing the silica oxide nanoparticles to the structure of poly(2-aminophenyldisulfide) strongly influences the electrochemical activity of the resulting composite [7]. What is more, the addition of $\mathrm{Al}_{2} \mathrm{O}_{3}$ to polyaniline polymer makes the resulting composite exhibit enhanced thermal stability [8]. As found by Chouli et al. [9], nanocomposite containing titanium oxide nanoparticles may be used for commercial applications as ingredient of antistatic and anticorrosion coatings. Daikh et al. [10] concluded that thanks to good electrical properties, PANI/ZnO nanocomposites may be applied in microwave frequencies as absorbing and shielding materials.

This work concerns the development of functional composites based on poly(vinyl alcohol) with the addition of zinc oxide nanoparticles, which have bactericidal and fungicidal properties. It is expected that the product will be applied on flat surfaces infected by microorganisms such as floors in changing rooms or baths, or overflow grates at a pool. The assumption is to obtain a material which will solidify after its application and which will be possible to tear off together with dead biological film.

\section{Materials and Methods}

\subsection{Materials}

The following compounds were used in this study: poly(vinyl alcohol) $(\mathrm{M}=72,000 \mathrm{~g} / \mathrm{mol}, \geq 99.0 \%)$, chitosan $(\mathrm{M}=100,000-300,000 \mathrm{~g} / \mathrm{mol}$, high purity), gelatin (p.p.a.), xanthan gum (p.p.a.), glycerine (d=1.26 g/ $\mathrm{cm}^{3}$, p.p.a.) methyl cellulose (viscosity $=400 \mathrm{cP}$, p.p.a), sucrose $(\geq 99.5 \%)$, zinc nitrate hexahydrate $(99.999 \%)$, sodium hydroxide $(\geq 98.0 \%)$. All compounds were provided by Sigma Aldrich, Germany. In microbiological tests, the following compounds were used: peptone, yeast extract, saccharose ( $\geq 98.0 \%)$, agarose. All compounds were provided by Sigma Aldrich, Germany. The Aspergillus niger and Saccharomyces cerevisiae strains used in the study were provided by the National Collection of Yeast cultures, England. All solutions were prepared using deionized water, Polwater, $0.18 \mu \mathrm{S}$.

\subsection{Methods}

\subsubsection{Preparation of Nanometric Zinc Oxide}

Nanoparticles of zinc oxide were obtained in a two-stage process. In the first stage, zinc hydroxide was precipitated by the reaction of zinc nitrate with sodium hydroxide. At the beginning, aqueous solutions of zinc nitrate at a concentration of $0.2 \mathrm{~mol} / \mathrm{dm}^{3}$ and sodium hydroxide at a concentration of $0.4 \mathrm{~mol} / \mathrm{dm}^{3}$ were prepared. Thereafter, $160 \mathrm{~cm}^{3}$ of zinc nitrate solution and $40 \mathrm{~cm}^{3}$ of sodium hydroxide were mixed in a stainless steel vessel of Parr 4525 pressure reactor to give zinc hydroxide. The process of dehydration of zinc hydroxide to zinc oxide was carried out for $30 \mathrm{~min}$ at $180{ }^{\circ} \mathrm{C}$. At the end of the process, the resulting nanometer zinc oxide was filtered under reduced pressure on Sartorius Stedim nitride-cellulose filters with a pore size of $0.45 \mu \mathrm{m}$. The sediment was washed several times with deionized water to wash out nitrate and sodium ions, and after the filtration was completed, the product was dried at $110^{\circ} \mathrm{C}$; after that it was triturated in an agate mortar. The obtained product was analyzed by scanning electron microscopy (SEM), Fourier transform infrared spectroscopy (FT-IR) and X-ray diffraction method (XRD). The SEM analysis was performed using 1430 VP microscope by LEO Electron Microscopy Ltd. The FT-IR analysis was performed using Nicolet 380 
spectrophotometer by Nicolet Co. The XRD analysis was performed using X-ray diffractometer X'Pert PW 1752/00 from Philips.

\subsubsection{Preparation of PVA-Based Composites with the Addition of Zinc Oxide Nanoparticles}

In the first step a reference composition was obtained. For this purpose aqueous solutions of individual components were prepared in accordance with Table 1.

In order to produce the reference composition, in a vessel with a capacity of $100 \mathrm{~cm}^{3} .20 \mathrm{~g}$ of an aqueous solution of poly(vinyl alcohol) at a concentration of $13 \%$ was prepared. The operation was carried out in a water bath at $60^{\circ} \mathrm{C}$. The components were mixed using a mechanical stirrer (Model OS40-S, ChemLand) at a setting of $600 \mathrm{rpm}$. The PVA was introduced in portions every $10 \mathrm{~s}$ for $1 \mathrm{~min}$. Then, the rest of ingredients was added according to the order given in Table 1. Table 1 also lists the final concentration of ingredients in the reference composition. After all the ingredients were introduced, the stirring speed was increased to $1000 \mathrm{rpm}$. The composition was mixed for $5 \mathrm{~min}$ from the time the first portion of PVA had been added. After stirring, the $\mathrm{pH}$ was checked and the consistency of the reference composition was evaluated.

The next step was to obtain compositions containing an active substance, which was a nanometric zinc oxide. In the studies the central-composition design was applied. It was generated in the Statistica ${ }^{\circledR}$ program, which is universal statistical software. The group of input parameters included: the process temperature, the concentration of glycerine and the concentration of zinc oxide nanoparticles in the final product. The ranges of variability of the process parameters were as follows:

- Temperature $\left({ }^{\circ} \mathrm{C}\right): 40,60$ or 80 ,

- $\mathrm{ZnO}$ concentration (\%): 1,3 or 5 ,

- Glycerine concentration (\%): 11, 14 or 17.
The concentrations were calculated into the mass of a pure $\mathrm{ZnO}$ added with accuracy to the hundredths and the volume of glycerine to the nearest decimal, remembering that its density is $1.26 \mathrm{~g} / \mathrm{cm}^{3}$. A complete list of individual parameters can be found in Table 2 .

Each composition was obtained in the same way. As in the case of the reference composition, the processes were carried out in a water bath using a mechanical stirrer. One by one, all the ingredients were introduced in accordance with the order given in Table 1. The last addition was zinc oxide nanoparticles, after which the stirring speed was increased to $1000 \mathrm{rpm}$. The total mixing time was $5 \mathrm{~min}$. After the process was completed, the compositions were applied to a flat polypropylene surface and allowed to dry for further testing. The obtained compositions were checked for physicochemical properties. The first test was density measurement. It was carried out using the weight method. Solid composites were also analyzed by scanning electron microscopy (SEM) with energy dispersion spectroscopy (EDS), which allowed to confirm the incorporation of zinc into the structure of composites. The XRD studies of the obtained products were performed as well. Rheological properties of the products were checked by determining flow curves and viscosity curves.

2.2.2.1 Study of Zinc Leaching from Composites In order to check the elution of zinc oxide from the resulting compositions, its accumulation in water was assessed. For this purpose composites in a solid form were used. It was assumed that for every $0.5 \mathrm{~g}$ of the product, $20 \mathrm{~cm}^{3}$ of deionized water which served as a washing medium was used. Table 2 shows individual quantities used in the research. In order to carry out the test, composites of known mass were placed in a $100 \mathrm{~cm}^{3}$ polypropylene vessel, and a metered amount of deionized water was added to them. Next, they were placed in a water bath located on a magnetic stirrer. The test was carried out at $32{ }^{\circ} \mathrm{C}$ by mixing the whole for $2 \mathrm{~h}$. After this time, all samples were filtered through a quantitative filter. To determine the concentration of the optionally released

Table 1 Ingredients of reference composition

\begin{tabular}{|c|c|c|c|c|}
\hline Compound & $\begin{array}{l}\text { Concentration in the } \\
\text { applied solution (\%) }\end{array}$ & Mass taken $(\mathrm{g})$ & $\begin{array}{l}\text { Mass of pure compo- } \\
\text { nent }(\mathrm{g})\end{array}$ & $\begin{array}{l}\text { Final concentration of the com- } \\
\text { pound in the reference sample } \\
(\%)\end{array}$ \\
\hline PVA & 13 & 20 & 2.6000 & 7.811 \\
\hline Suchrose & 2 & 2 & 0.0400 & 0.120 \\
\hline Methyl cellulose & 0.1 & 1.5 & 0.0015 & 0.005 \\
\hline Xanthan gum & 0.5 & 1 & 0.0050 & 0.015 \\
\hline Gelatin & 1 & 2 & 0.0200 & 0.060 \\
\hline Chitosan & 0.2 & 2 & 0.0040 & 0.012 \\
\hline Glycerine & 100 & 4.788 & 4.7880 & 14.384 \\
\hline Solvent (summary value) & - & - & 25.8295 & 77.594 \\
\hline
\end{tabular}


Table 2 Parameters of the processes for the preparation of the composition with the addition of zinc oxide nanoparticles

\begin{tabular}{|c|c|c|c|c|c|c|}
\hline \multirow[t]{2}{*}{ Run } & \multicolumn{3}{|c|}{ Input parameters } & \multicolumn{3}{|c|}{ Output parameters } \\
\hline & $\begin{array}{l}\text { Tempera- } \\
\text { ture }\left({ }^{\circ} \mathrm{C}\right)\end{array}$ & $\begin{array}{l}\text { Concentration of } \\
\text { nano- } \mathrm{ZnO}(\%)\end{array}$ & $\begin{array}{l}\text { Concentration of } \\
\text { glycerine }(\%)\end{array}$ & Density $\left(\mathrm{g} / \mathrm{cm}^{3}\right)$ & $\begin{array}{l}\text { Concentration of zinc eluted } \\
\text { from composites }\left(\mathrm{mg} / \mathrm{dm}^{3}\right)\end{array}$ & $\begin{array}{l}\text { Strength needed to tear } \\
\text { off the composites }(\mathrm{kPa})\end{array}$ \\
\hline $\mathrm{C} 1$ & 40 & 1 & 11 & 1.07 & 4.2 & 7.6 \\
\hline $\mathrm{C} 2$ & 40 & 1 & 17 & 1.07 & 4.1 & 79.1 \\
\hline $\mathrm{C} 3$ & 40 & 5 & 11 & 1.09 & 3.6 & 81.5 \\
\hline $\mathrm{C} 4$ & 40 & 5 & 17 & 1.10 & 2.3 & 48.7 \\
\hline $\mathrm{C} 5$ & 80 & 1 & 11 & 1.08 & 4.3 & 11.6 \\
\hline C6 & 80 & 1 & 17 & 1.08 & 3.7 & 43.9 \\
\hline $\mathrm{C} 7$ & 80 & 5 & 11 & 1.11 & 0.8 & 9.8 \\
\hline $\mathrm{C} 8$ & 80 & 5 & 17 & 1.12 & 0.6 & 42.8 \\
\hline C9 & 40 & 3 & 14 & 1.08 & 2.1 & 131.2 \\
\hline $\mathrm{C} 10$ & 80 & 3 & 14 & 1.11 & 1.8 & 111.6 \\
\hline $\mathrm{C} 11$ & 60 & 1 & 14 & 1.07 & 4.4 & 21.4 \\
\hline $\mathrm{C} 12$ & 60 & 5 & 14 & 1.11 & 1.3 & 12.6 \\
\hline $\mathrm{C} 13$ & 60 & 3 & 11 & 1.09 & 1.3 & 18.6 \\
\hline $\mathrm{C} 14$ & 60 & 3 & 17 & 1.09 & 1.9 & 147.3 \\
\hline C15 & 60 & 3 & 14 & 1.09 & 1.7 & 17.3 \\
\hline $\mathrm{C} 16$ & 60 & 3 & 14 & 1.10 & 2.2 & 20.4 \\
\hline Ref. & & & & 1.03 & 0.0 & 86.0 \\
\hline
\end{tabular}

zinc, the filtrates were analyzed by means of inductively coupled atomic emission spectroscopy (ICP-OES).

\subsubsection{Study of Zinc Penetration Through a Model Dermal}

Membrane According to the literature data, nanoparticle zinc oxide penetrates into the cells of organisms, which can be also dangerous for people. Tests were designed to check the amount of zinc released from composites and whether its penetration through the material imitating human skin was possible. The Strat-M® Membrane for Transdermal Diffusion Testing was used. Two research series were performed in which Ringer's solution and SBF solution played the role of acceptor fluids. They were prepared according to the literature data $[11,12]$. The stand consisted of a magnetic stirrer with a heating plate, a water bath, a polypropylene vessel with a capacity of $100 \mathrm{~cm}^{3}$, in which there was an acceptor liquid of appropriate volume and a plastic column with a diameter of $2.5 \mathrm{~cm}$, at the end of which the membrane was mounted (Fig. 1).

Prior to the study, composites with a known surface area were prepared. Next, the amount of deionized water applied was calculated assuming that $1 \mathrm{~cm}^{2}$ of the sample contacts with $3 \mathrm{~cm}^{3}$ of deionized water and the amount of acceptor fluid was assessed, with the assumption that $1 \mathrm{~cm}^{2}$ of the sample corresponds to $20 \mathrm{~cm}^{3}$ of the accepting solution. The study was carried out according to a predetermined pattern. First, an appropriate amount of acceptor fluid with a mixing element was placed in a polypropylene container which was placed in a water bath at

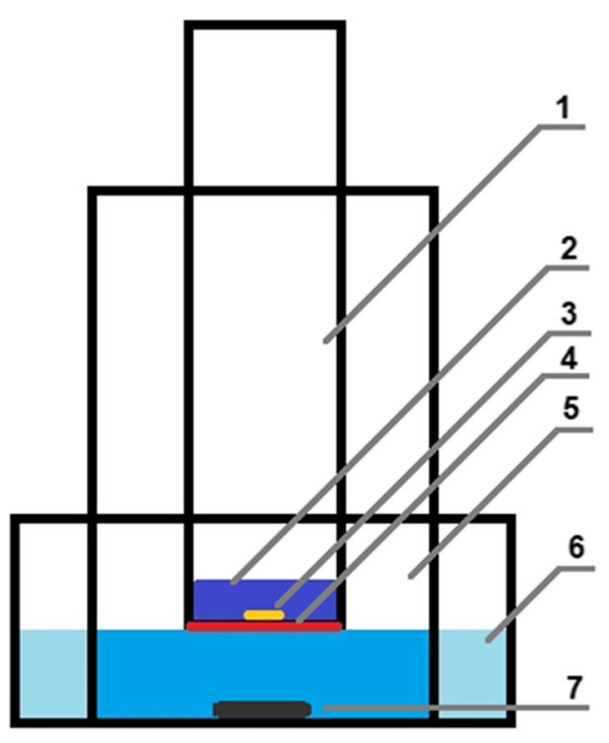

Fig. 1 Stand for testing the penetration of zinc oxide nanoparticles: 1 - column, 2-deionized water, 3-tested composite, 4-model dermal membrane, 5-container with acceptor liquid, 6-water bath, 7-stirrer

a constant temperature of $39{ }^{\circ} \mathrm{C}$. Next, a column with the Strat-M® membrane in which the prepared composite had been placed was mounted. A metered amount of deionized water was introduced into the column and positioned so that the membrane touched the acceptor fluid surface. The system was mixed at $400 \mathrm{rpm}$ for $20 \mathrm{~min}$. After the test 
the ICP-OES was used for the analysis of presence of all elements in the acceptor fluid.

2.2.2.3 Study of Adhesive Properties The obtained product is intended to be applied to surfaces infected by pathogenic microorganisms. After a few hours of application, the liquid composition solidifies and can be detached from the surface. In order to check which force should be applied to tear off the dried composite, the testing of adhesive properties was carried out.

At the beginning of the study, a structure was designed and constructed to examine the force needed to tear off the obtained composites from the polypropylene surface.

Composites in a form of suspension were applied onto a polypropylene surface, assuming that $0.5 \mathrm{~cm}^{3}$ of the composition corresponds to $0.5 \mathrm{~cm}^{2}$ of the surface. After solidification of the composite, a force needed to tear off the composite was measured using a Zwick 1445 testing machine.

2.2.2.4 Microbiological Studies The antifungal activity of nanoparticles in the prepared composites was studied in the course of microbiological tests against Aspergillus niger. This strain is commonly used in microbiological studies as a model species as it is one of the most intensively studied and known eukaryotic organisms [13]. The A. niger strain was cultured at $30{ }^{\circ} \mathrm{C}$ for 14 days in a Petri dish containing a growth medium. In the passaging stage, the cells were transferred to sterile $250 \mathrm{~cm}^{3}$ flasks containing $50 \mathrm{~cm}^{3}$ of fluid growth medium and $0.07 \mathrm{~g}$ of the obtained composites or reference composite which did not contain nanoparticles. The cultures were incubated in a rotary shaker at appropriate temperatures not exceeding $30{ }^{\circ} \mathrm{C}$. Cell growth was studied by measuring the increasing optical density using a spectrophotometer at a wavelength of $540 \mathrm{~nm}$. Measurements were performed consecutively for $48 \mathrm{~h}$ at the same time each day.

\section{Results}

\subsection{Nanometric Zinc Oxide}

Figure 2 shows results of the analysis of zinc oxide physicochemical properties.

The shape of $\mathrm{ZnO}$ nanoparticles can be seen in a micrograph (Fig. 2a) from scanning by electron microscopy. They have a diverse size ranging from several dozen to several $100 \mathrm{~nm}$. Results of the XRD analysis (Fig. 2b) showed that pure zinc oxide was obtained, as evidenced by reflections at angles of $2 \theta=31.7^{\circ}, 34.4^{\circ}, 36.2^{\circ}, 47.5^{\circ}$ and $56.5^{\circ}$. In Fig. $2 \mathrm{c}$ one may observe a characteristic peak at a wavenumber of approximately $400 \mathrm{~cm}^{-1}$, corresponding to the $\mathrm{Zn}-\mathrm{O}$ bond. In addition, the peak at a wavenumber of about $3500 \mathrm{~cm}^{-1}$ is derived from vibrations of the $\mathrm{OH}$ group. Probably there were residual amounts of zinc hydroxide in the sample.
Fig. 2 a SEM microphotography, b XRD diffractogram, c FT-IR spectra of obtained zinc oxide
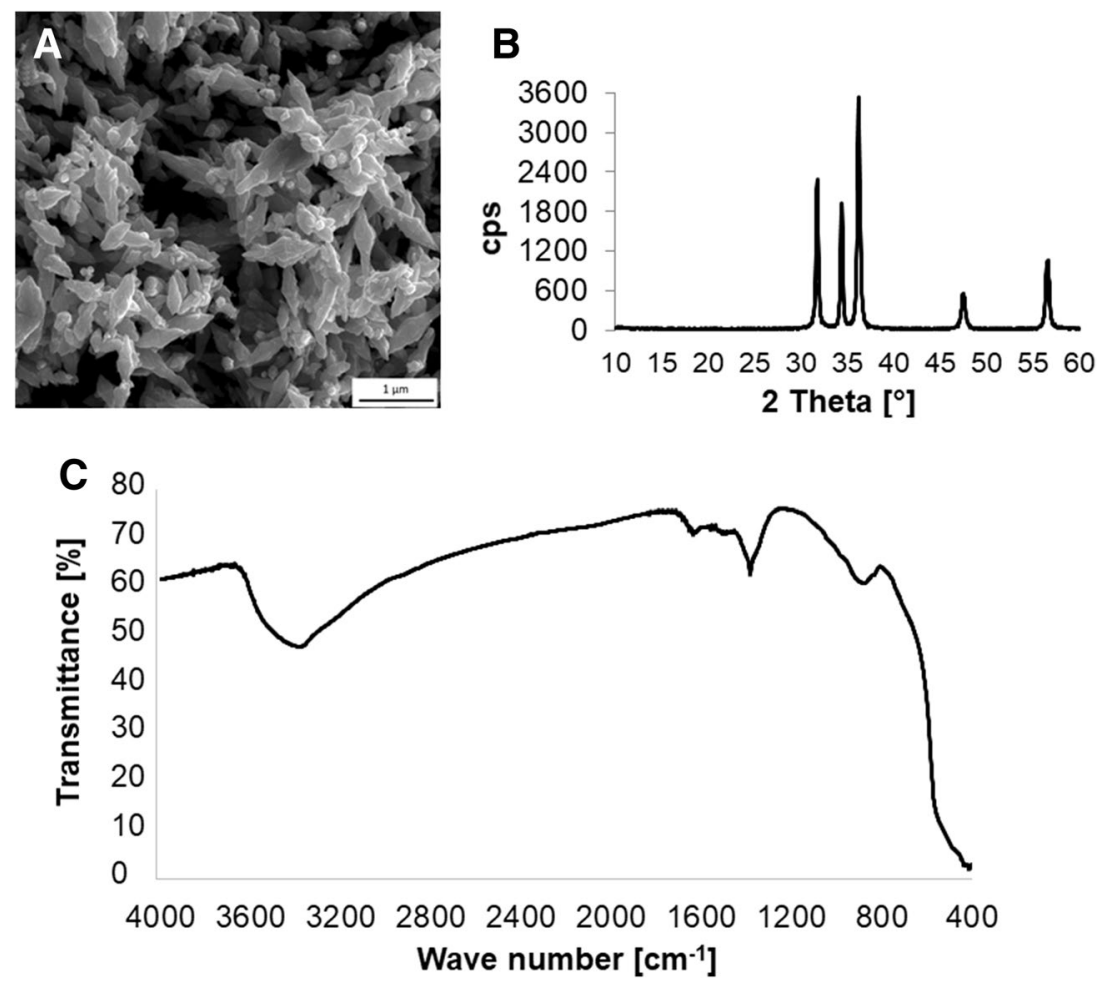


\subsection{PVA-Based Composites with the Addition of Zinc Oxide Nanoparticles}

White suspensions with undifferentiated density were obtained (Table 2). Basically, the greater amount of glycerine was used, the greater was the density of the obtained products.

Mappings of surfaces of the selected products are presented in Fig. 3 and results of the SEM-EDS analysis are provided in Fig. 4.

Thanks to the mapping and the SEM-EDS technique it was possible to determine the elemental composition and to visualize the surface of the selected materials. As expected, significant amounts of zinc oxide were identified in the selected samples of composites while in the reference sample mainly oxygen and carbon from other components were identified.

Figure 5 contains a collective plot of X-ray diffractometry analysis results. In all products, excluding the reference sample, the peaks characteristic for zinc oxide are visible at the angles between $30^{\circ}$ and $60^{\circ}$. There is also a visible relationship between the intensity of counts and the percentage of $\mathrm{ZnO}$. The highest peaks appeared in samples containing $5 \%$ of nanometric zinc oxide.

The selected samples were tested for rheological properties. Figure $6 \mathrm{a}$ shows viscosity curves, Fig. $6 \mathrm{~b}$ shows flow curves. All composites exhibit similar properties. The addition of zinc oxide does not affect the rheological properties of the obtained products. This is desired due to their application properties.

\subsubsection{Study of Zinc Leaching from Composites}

The percentage share of zinc that is eluted from composites (Table 2) does not exceed 5\%. This is a desired result since antimicrobial properties are not weakened due to the release of zinc. The results of this study were subjected to statistical analysis which aimed at indicating independent parameters significantly affecting the obtained data.

\subsubsection{Zinc Penetration Through a Model Dermal Membrane}

In all cases the concentration of zinc ions in acceptor liquids used in the study of the penetration of zinc through a model
Fig. 3 Mappings of obtained composites: a C Ref., b C3, c $\mathrm{C} 4, \mathbf{d} \mathrm{C} 8$, e C12, f C15
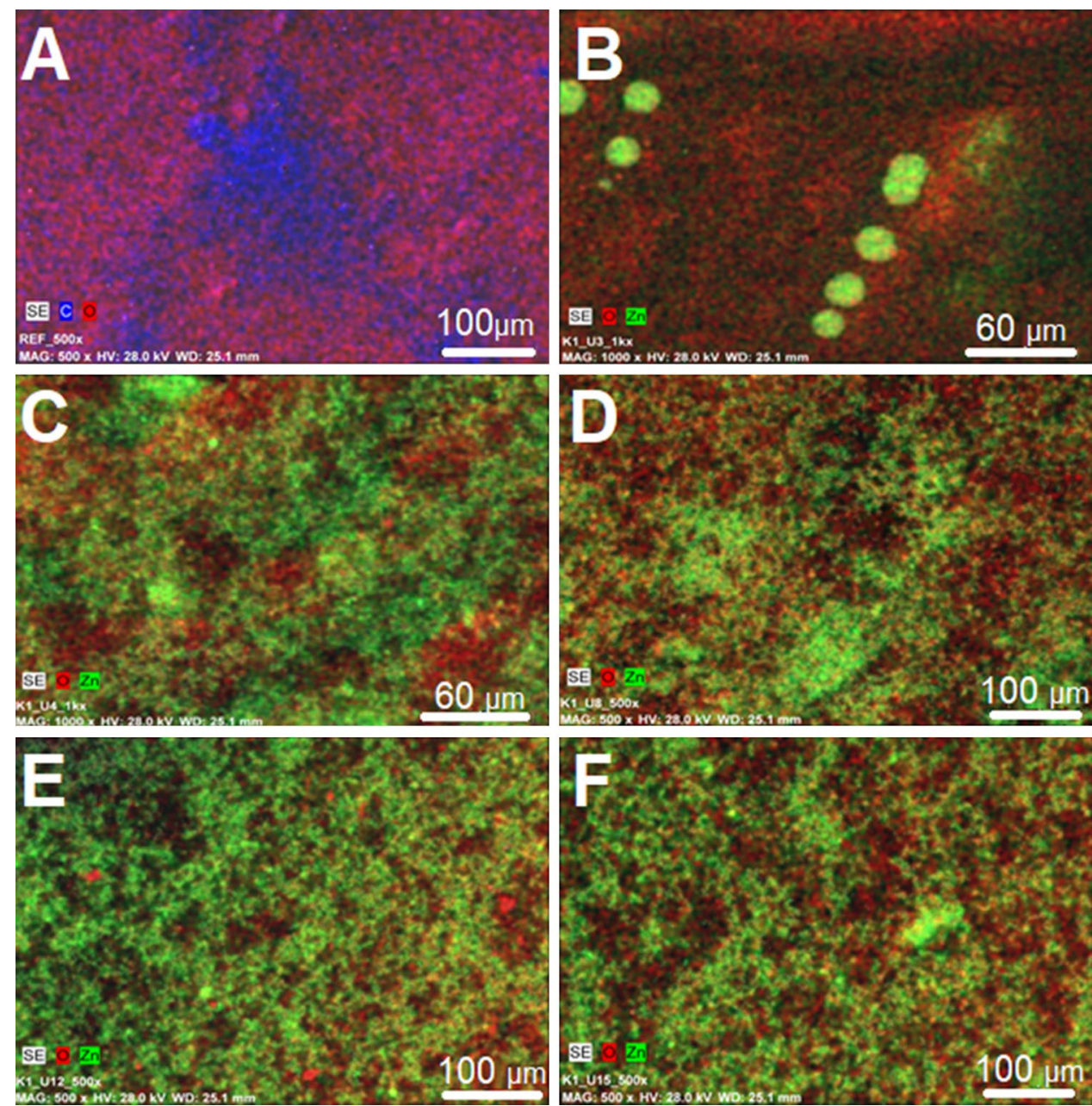


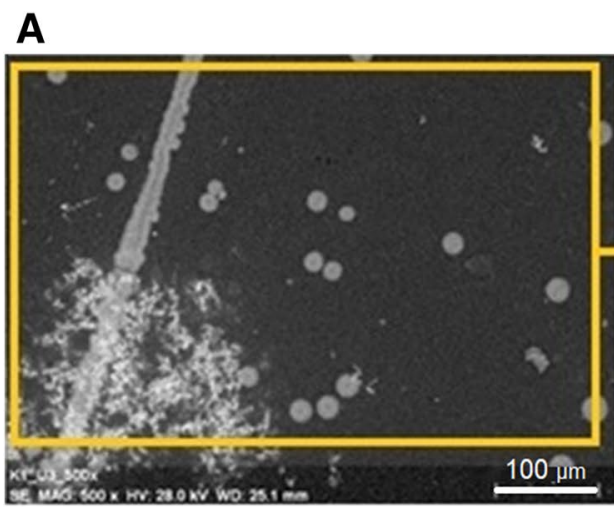

B

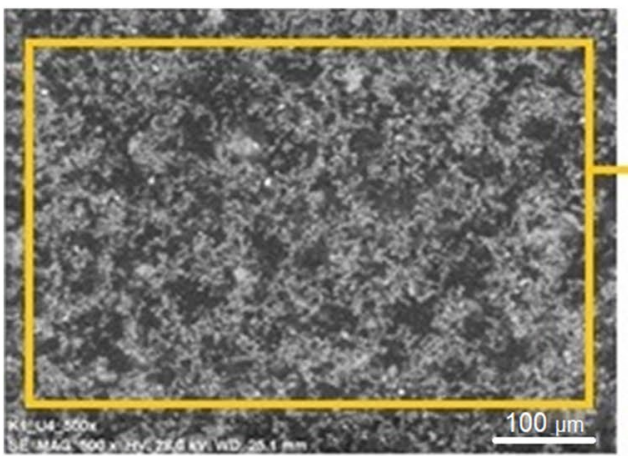

C

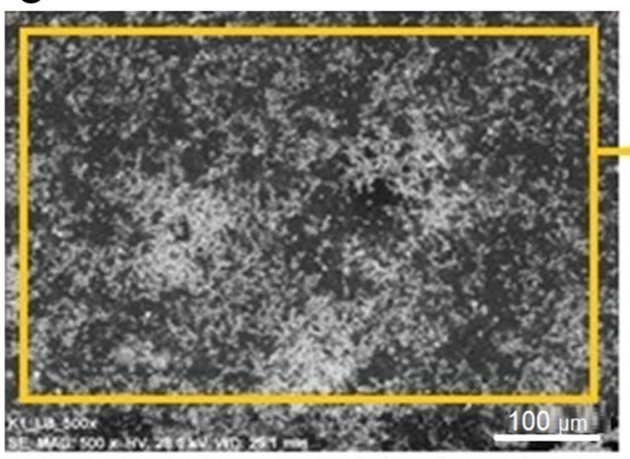

D

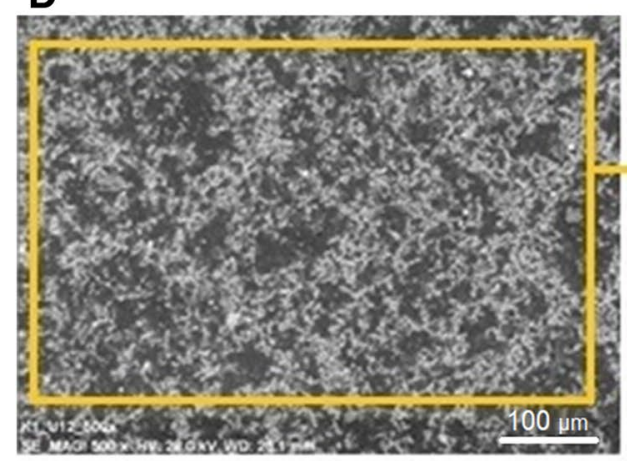

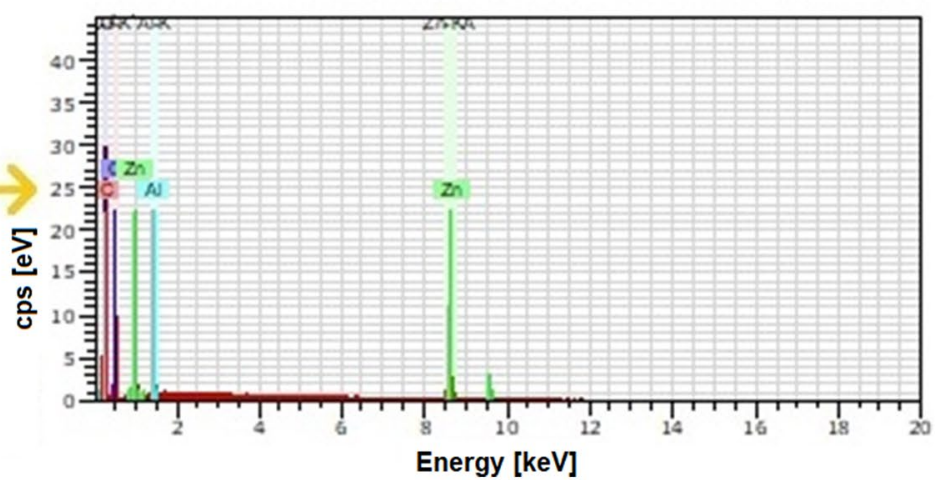
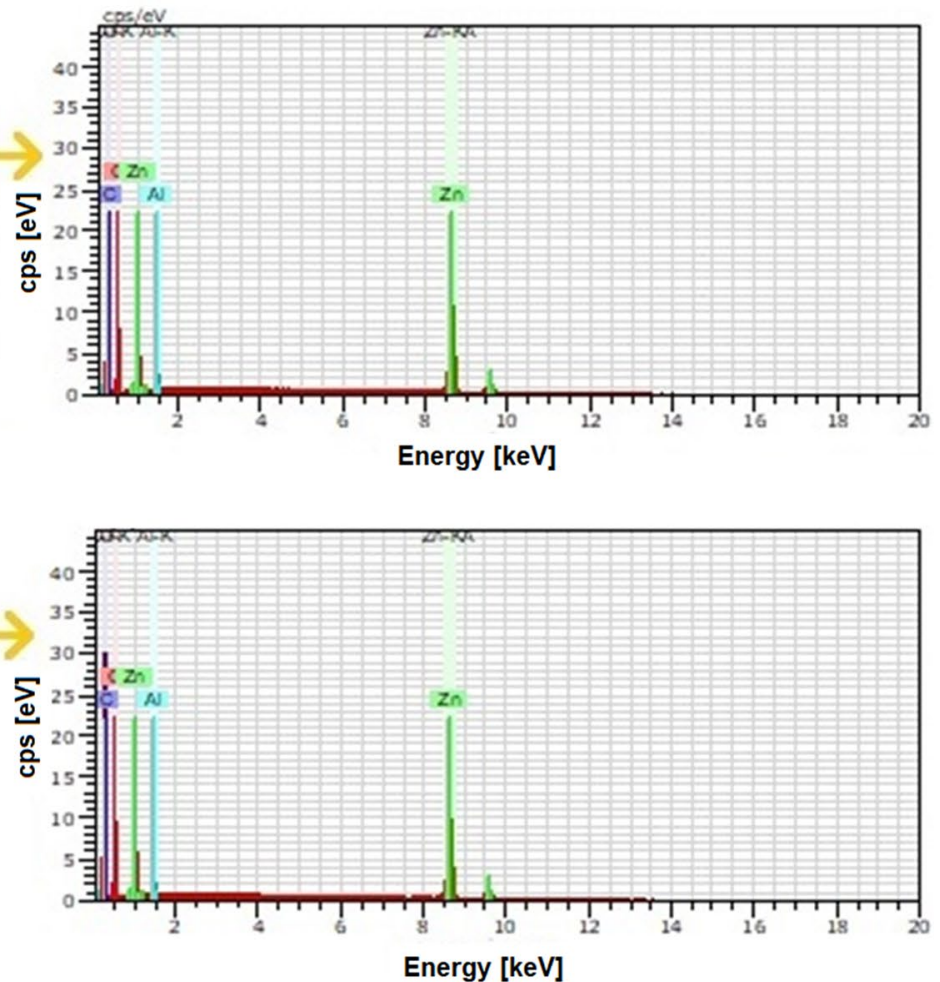

Energy [keV]

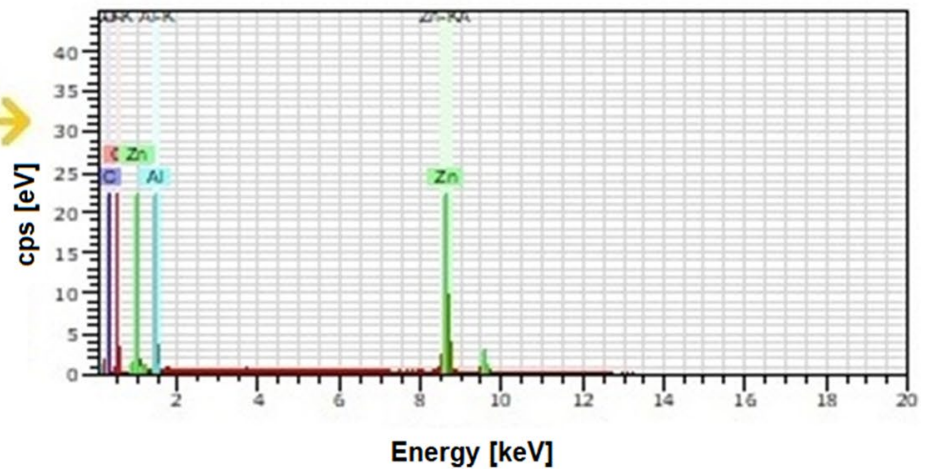

Fig. 4 Results of SEM-EDS analysis: a C3, b C4, c C8, d C12, e C15 

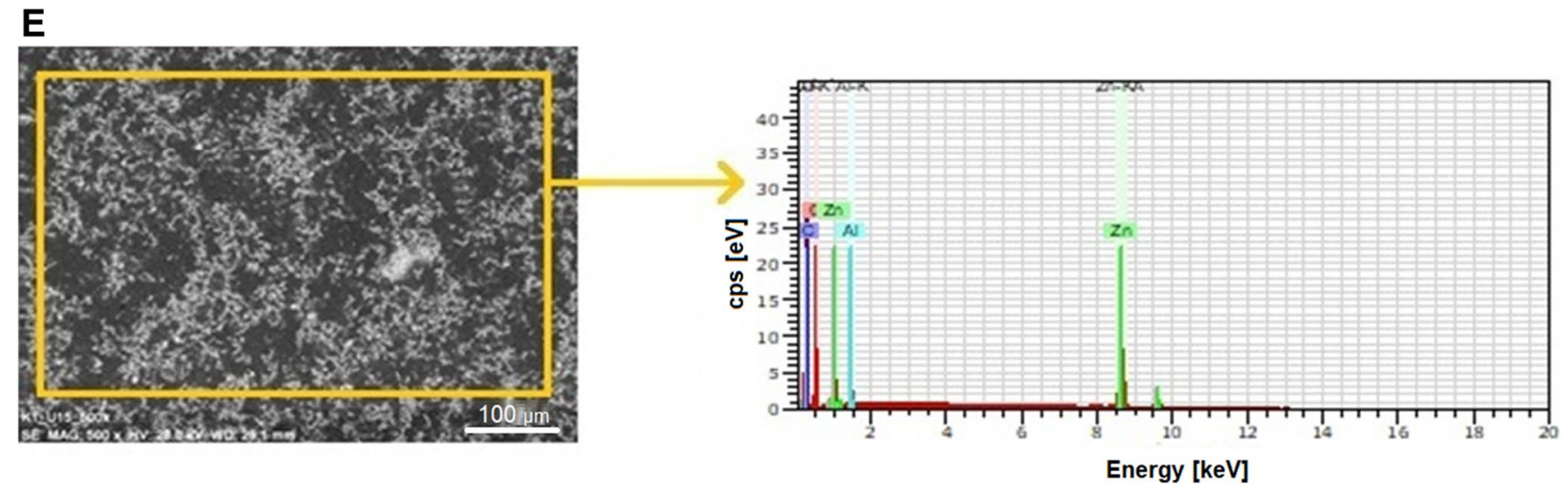

Fig. 4 (continued)

Fig. 5 Results of XRD analysis of all composites

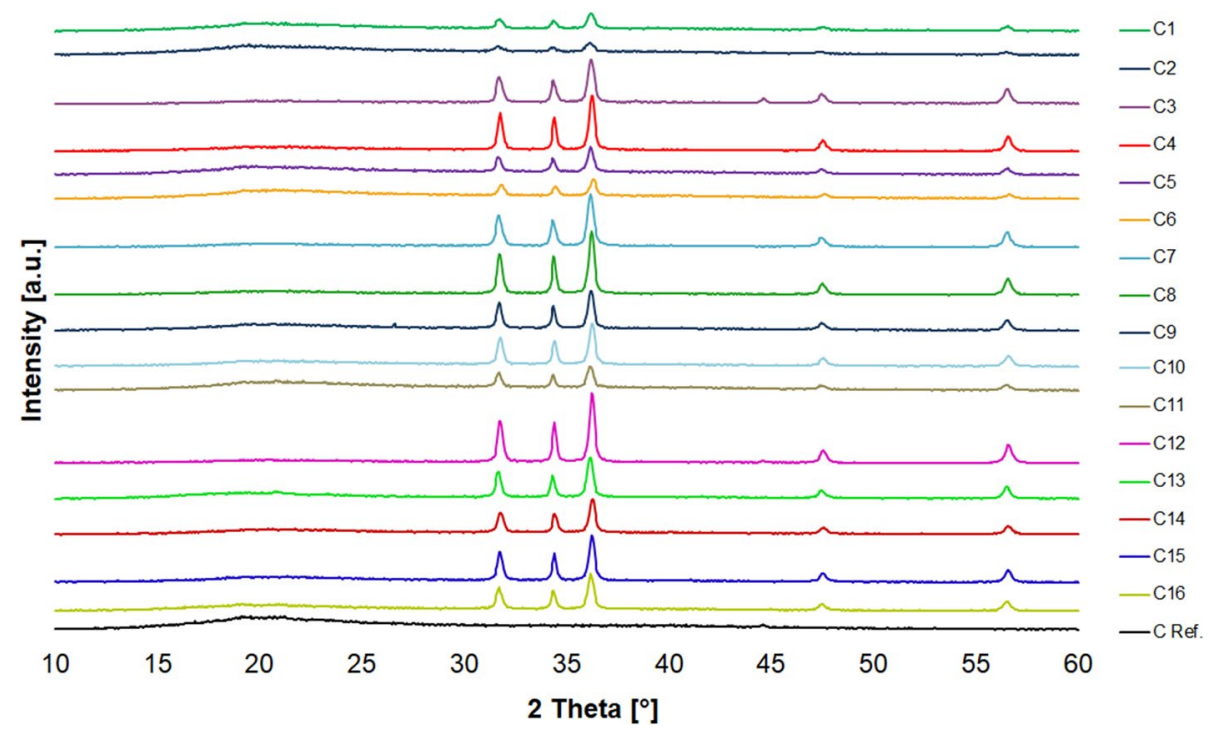

dermal membrane was below the limit of quantification. That means that the active substance in a form of nanometric zinc oxide is not able to penetrate the skin of humans who have contact with the applied coatings.

\subsubsection{Adhesive Properties}

The study examined the strength that is needed to tear off the solidified composite coatings from a polypropylene surface. The results are included in Table 2. The influence of independent factors was checked during statistical analysis. The results indicate that the strength needed to tear off the composition is low. This is a beneficial situation because dried coatings could be removed easily.

\subsubsection{Microbiological Properties}

The results of optical density are presented in Fig. 7.

The addition of zinc oxide nanoparticles has a high impact on the viability and growth ability of the A. niger strain. It was revealed that all composites with zinc oxide nanoparticles inhibited the growth of the A. niger strain in the course of the analysis. The best results after $24 \mathrm{~h}$ were obtained in the case of $\mathrm{C} 1, \mathrm{C} 2, \mathrm{C} 5$ and $\mathrm{C} 11$ composites. The values of growth inhibition for these samples were: $94.8 \%, 92.0 \%, 91.7 \%$ and $91.4 \%$, respectively. It was figured out that $\mathrm{C} 8$ and $\mathrm{C} 6$ exhibited the worst antifungal activity. The growth inhibition for them was equal to $0.3 \%$ and $38.6 \%$. After $48 \mathrm{~h}$ the following growth inhibition values were obtained: $91.2 \%$ for $\mathrm{C} 11,83.0 \%$ for $\mathrm{C} 10,73 \%$ for $\mathrm{C} 1$ and $65.3 \%$ for C5. Samples C4 (7.2\%) and C8 (15.8\%) had a weaker antifungal activity. The difference in inhibition 

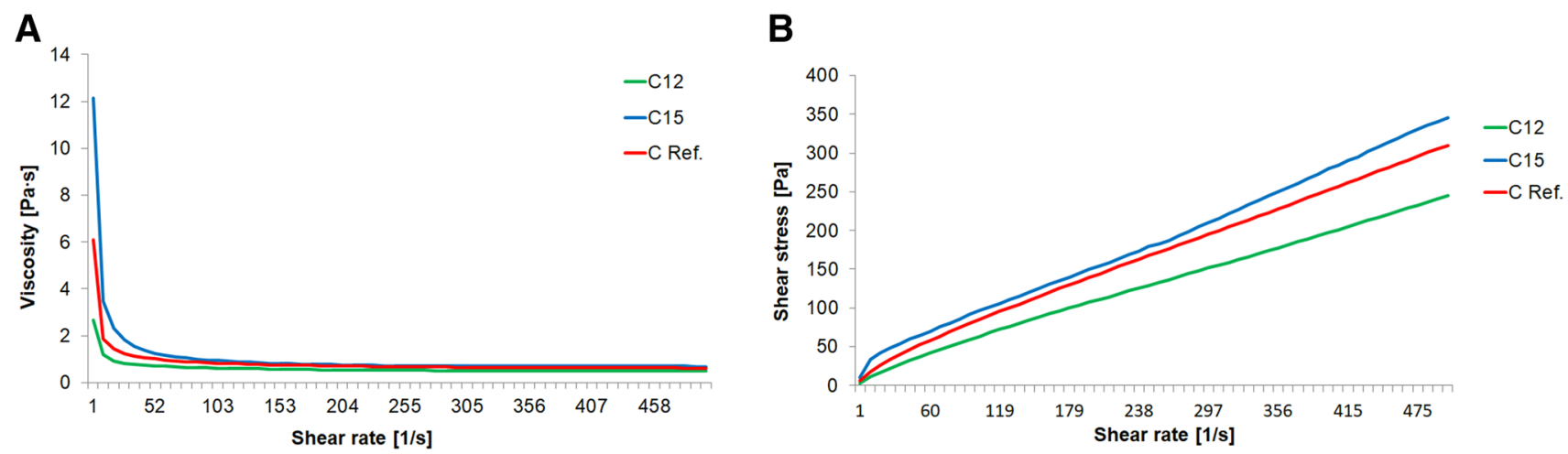

Fig. 6 Results of viscosity properties: a viscosity curves, $\mathbf{b}$ flow curves

Fig. 7 Results of optical density measurements at $\lambda=540 \mathrm{~nm}$

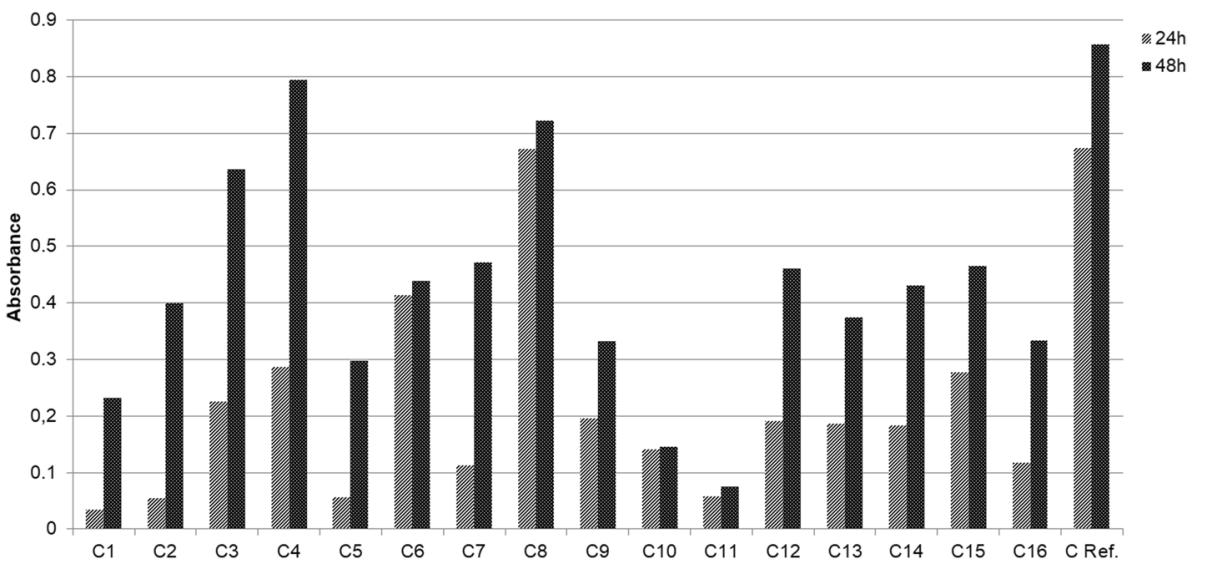

between samples is probably related to the ability of leaching of nanoparticles from composites to the culture medium. This is because the biological material was incubated in a liquid medium. To sum up, composite C8 was found as the best antifungal composition. It is directly related to the fact that the concentration of zinc eluted from this composite was equal to $4.4\left(\mathrm{mg} / \mathrm{dm}^{3}\right)$ which was the highest value. The antimicrobial effect of PVA/ZnO nanocomposites was also confirmed by other scientists. Ahangar et al. [14] evaluated biocidal effect of such composites against the $E$. coli strain. The addition of zinc oxide nanoparticles to PVA resulted in the intensification of bacterial growth inhibition.

\subsection{The Influence of Input Parameters on Properties of Obtained Composites}

Statistical analysis was performed based on one-way analysis of variance (ANOVA). In order to evaluate the significance of the differences, an F-test was used. A value of $\mathrm{p}<0.05$ was established as significant in all cases. The profiles of the utility function with respect to certain independent parameters, thanks to which it was possible to determine changes in the dependent parameters when changing the values of independent parameters, were prepared.

The resulting approximation profiles allow us to provide specific values of input factors that ensure the most desirable (useful) estimated values of output factors. Approximated values are converted into a utility scale which includes the values of 0 (undesired effects) to 1 (desired effects). Thanks to the obtained approximation profiles, it was possible to optimize the usability of this product.

Figure 8 presents the Pareto charts for input parameters. Parameters which are statistically significant for the established $p$ value $(\mathrm{p}<0.05)$ are marked with a red line.

The concentration of glycerine in square function is the parameter which affects the elution of zinc from composites. As found by other researchers, the addition of metallic oxide nanoparticles to a polymer matrix has a great importance in creating their physicochemical and mechanical properties [15]. However, the force needed to tear off the composites from a polypropylene surface is dependent only on the temperature of samples prepared in linear function. The approximation profiles are presented in Fig. 9.

Based on an assessment of the approximation profiles, the influence of independent parameters on dependent variables 

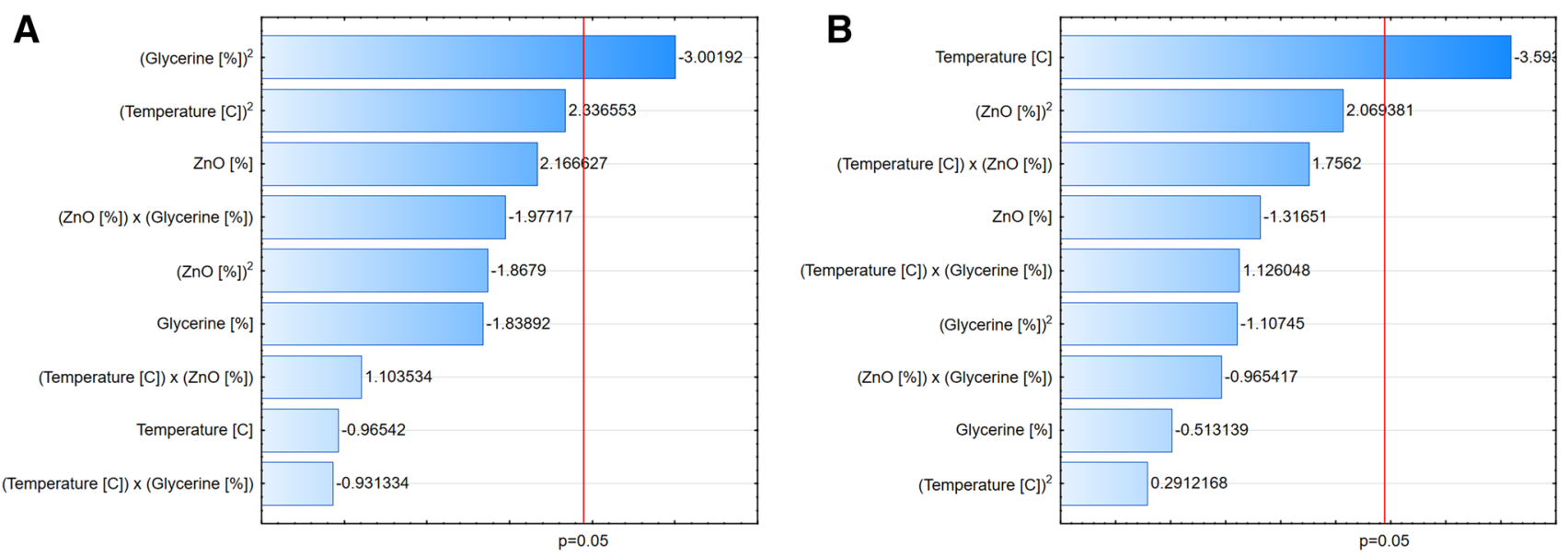

Fig. 8 Pareto charts for influence of input parameters on: a zinc leaching from composites, $\mathbf{b}$ strength needed to tear off composites

and determination of the specific values of input parameters ensure that reaching desired values of the output parameters is possible. Both the lower elution of zinc from composites and lower strength needed to tear off the composites are more desirable. When glycerine concentration influences the elution rate, one may observe an inflection point. Initially, when this value increases, the elution rate increases as well. After glycerine concentration reaches a value of 12.5, the elution rate begins to decay. Thus the most desired value of glycerine - in order to inhibit the release of zinc-among the tested values is equal to $17.0 \%$. Therefore, the general conclusion is that the presence of glycerine favours the remaining zinc in composites. This may be due to the fact that glycerine which was used as thickening agent caused zinc to have a weaker ability to migrate from composites.

The influence of temperature on force needed to tear off the composites was as follows: a higher temperature caused decreasing of adhesive properties. This may be due to the fact that products obtained at a higher temperature were more flexible and thus the strength of their binding with the surface was weaker.

\section{Discussion}

The role of components in the prepared products was of crucial significance. Gelatin and guar gum swell in an aqueous medium, which leads to changes of suspension viscosity. By the addition of cellulose derivatives it was possible to form thixotropic gels that exhibited resistance to gravity. This feature is particularly desirable when it comes to coating, for example, ceilings. It is worth noting that the use of the substances mentioned above provided additional protection against agglomeration of dispersed zinc oxide nanoparticles $[16,17]$. The adsorption of molecules of the said compounds on the surface of metal oxide nanoparticles gave them a surface charge that favours the electrostatic repulsion, which makes them kinetically stable. In order to increase the affinity of the resulting nanocomposite for a microbiological biofilm, it was necessary to add a substance for achieving the "hook effect". Extracellular polymers play a special role in the phenomenon of microbial adhesion to any surface. This group of compounds includes, inter alia, lipopolysaccharides and proteins. It is expected that the enrichment of the composition with compounds such as casein (protein), sucrose (carbohydrate) or chitosan (polysaccharide) will increase the adhesion of the biofilm to the applied material. It should be noted that the adhesion of microbial cells is a multistep process. It is affected by hydrodynamic forces, gravity, thermodynamic (Brownian motion) forces and van der Waals forces. The last ones favour efficient attraction of cells to the material surface. When the microbial cells are in a distance less than $1.5 \mathrm{~nm}$ from the material surface, then specific hydrogen bonding and covalent carbon-carbon bonds are formed. A chemical interaction of substances such as casein, sucrose, or chitosan with extracellular polymers that are produced by the microbial biofilm ensures better adhesion of the sprayed material [18-20].

Taking into consideration utility properties of the obtained products, the composition with best properties may be highlighted. This is composition $\mathrm{C} 8$ which was prepared at the highest temperature and when the concentrations of both glycerine and zinc oxide were the highest. However, this composite does not have the best antifungal properties. Taking into consideration all the desired properties, composite C10 may be highlighted as the best material.

\section{Conclusion}

At the beginning, nanometric zinc oxide was obtained by the hydrothermal method. The conducted analyses confirmed the purity of the obtained material. In the next part, the reference 
Fig. 9 Approximation profiles for influence of input parameters on: a zinc leaching from composites, $\mathbf{b}$ force needed to tear off composites
A

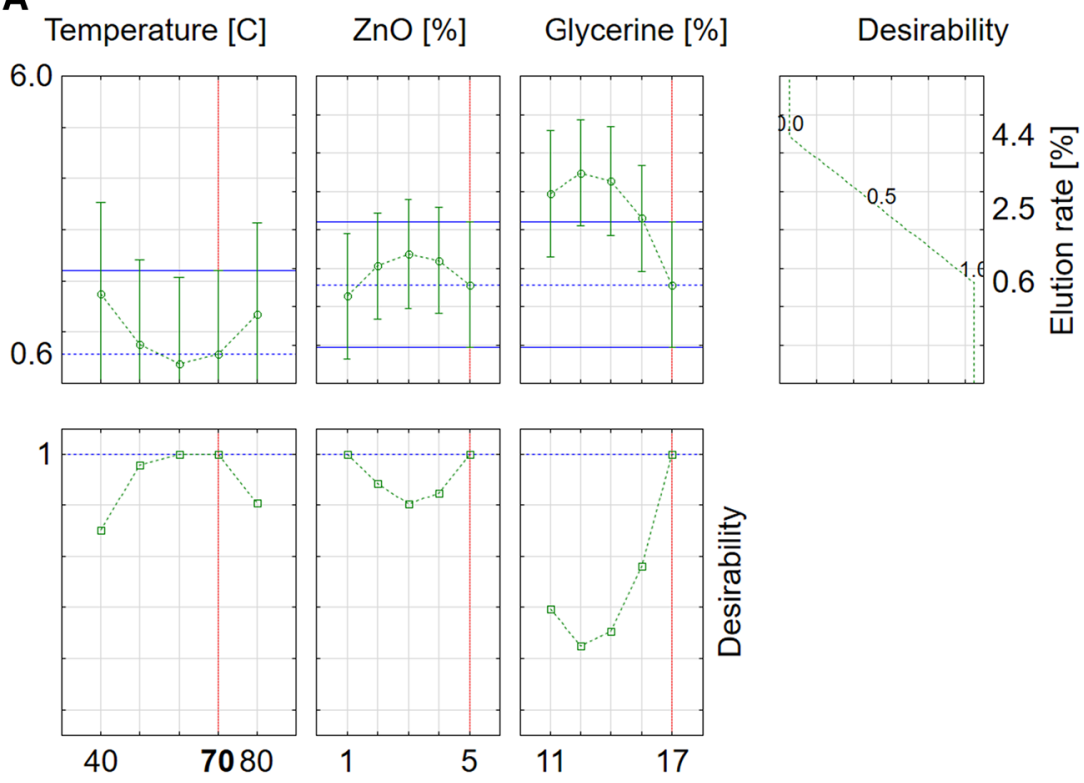

\section{B}

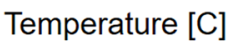

\section{$\mathrm{ZnO}[\%]$}

Glyceryne [\%]

Desirability
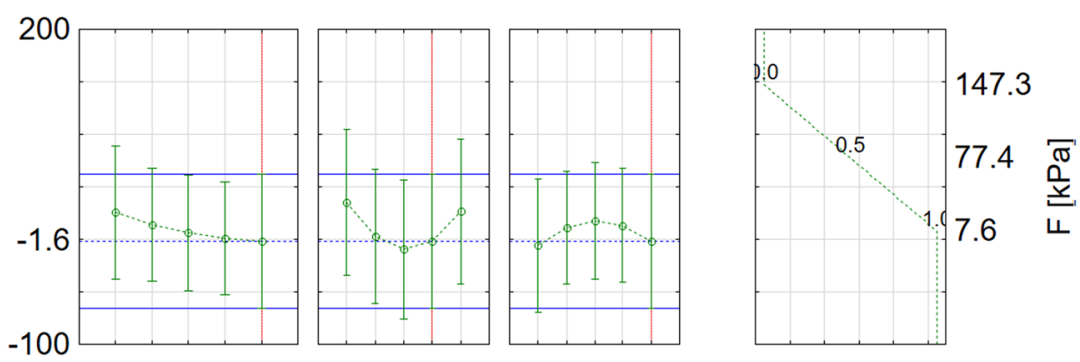

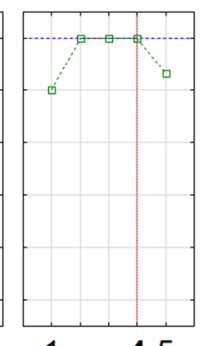

$\begin{array}{llll}1 & 45 & 11 & 17\end{array}$

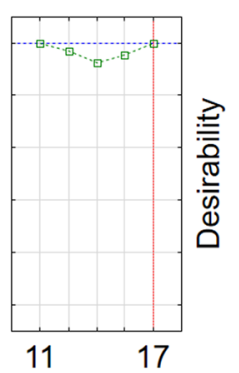

composition was developed, which was the basis for further research. The main ingredient was poly(vinyl alcohol), characterized by good solubility in water. The next step was to obtain 16 compositions containing the active substance that was previously prepared-zinc oxide nanoparticles. The adopted methodology allowed satisfactory incorporation of nanometric zinc oxide into the composite structure, as evidenced by the relatively low values of zinc concentration in the eluent solutions. In the last stage, samples of all compositions were analyzed for their physicochemical and utility properties. The penetration of zinc through model dermal membranes was also checked. In addition, microbiological tests were carried out for antifungal properties. The obtained composites have antimicrobial properties. After 24 and $48 \mathrm{~h}$ from application, a negative difference in the growth of $A$. niger was seen in comparison to the reference sample.

Acknowledgements The work is the result of the research Project No. UMO-2016/23/D/ST8/00016 funded by the National Science Centre, Poland.

\section{Compliance with Ethical Standards}

Conflict of interest The authors declare that there is no conflict of interests regarding the publication of this article. 
Open Access This article is distributed under the terms of the Creative Commons Attribution 4.0 International License (http://creativeco mmons.org/licenses/by/4.0/), which permits unrestricted use, distribution, and reproduction in any medium, provided you give appropriate credit to the original author(s) and the source, provide a link to the Creative Commons license, and indicate if changes were made.

\section{References}

1. M. Al Hasan, S.M. Fitzgerald, M. Saoudian, G. Krishnaswamy, Curr. Opin. Infect. Dis. 2, 1 (2004)

2. A.S. Weissfeld, Clin. Microbiol. Newsl. 37, 87 (2015)

3. J. You, Y. Zhang, Z. Hu, Colloids Surf. B 85, 161 (2011)

4. K. Varaprasad, G.M. Raghavendra, T. Jayaramudu, J. Seo, Carbohydr. Polym. 135, 349 (2016)

5. M.I. Abd-Elrahman, Nanoscale Microscale Thermophys. Eng. 17, 194 (2013)

6. F.Z. Dahou, M.A. Khaldi, A. Zehhaf, A. Benyoucef, M.I. Ferrahi, Adv. Polym. Technol. 35, 1 (2016)

7. S. Benyakhou, A. Belmokhtar, A. Zehhaf, A. Benyoucef, J. Mol. Struct. 1150, 580 (2017)

8. S. Benykhlef, A. Bekhoukh, R. Berenguer, A. Benyoucef, E. Morallon, Colloid Polym. Sci. 294, 1877 (2016)

9. F. Chouli, I. Radja, E. Morallon, A. Benyoucef, Polym. Compos. 38, E254 (2017)
10. S. Daikh, F.Z. Zeggai, A. Bellil, A. Benyoucef, J. Phys. Chem. Solids 121, 78 (2018)

11. S. Jalota, S.B. Bhaduri, A. Cuneyt Tas, Mater. Sci. Eng. C 28, 129 (2008)

12. S. Kumar, T.S.N. Sankara Narayanan, S. Ganesh Sundara Raman, S.K. Seshadri, Corros. Sci. 52, 711 (2010)

13. H.L. Hu, J. van den Brink, B.S. Gruben, H.A.B. Wösten, J.D. Gu, R.P. de Vries, Int. Biodeterior. Biodegrad. 65, 248 (2011)

14. E.G. Ahangar, M.H. Abbaspour-Fard, N. Shahtahmassebi, M. Khojastehpour, P. Maddahi, J. Food Process. Preserv. 39, 1442 (2015)

15. K. Yamani, R. Berenguer, A. Benyoucef, E. Morallon, J. Therm. Anal. Calorim. (2018). https://doi.org/10.1007/s1097 3-018-7347-z

16. D. Saha, S. Bhattacharya, J. Food Sci. Technol. 47, 587 (2010)

17. T. Wüstenberg, General Overview of Food Hydrocolloids, in, Cellulose and Cellulose Derivatives in the Food Industry: Fundamentals and Applications (Wiley, Weinheim, 2014)

18. I. Dogsa, M. Kriechbaum, D. Stopar, P. Laggner, Biophys. J. 8, $2711(2005)$

19. A. Shanmugam, K. Kathiresan, L. Nayak, Biotechnol. Rep. 9, 25 (2016)

20. I. Armentano, C.R. Arciola, E. Fortunati, D. Ferrari, S. Mattioli, C.F. Amoroso, J.M. Kenny, M. Imbriani, L. Visai, Sci. World. J. 410423, 18 (2014) 